\title{
Use of Mixed Methods Designs in Substance Research: A Methodological Necessity in Nigeria
}

\author{
Emeka W. Dumbili
}

Brunel University, London (emeka.dumbili@brunel.ac.uk; favourfredy@yahoo.com)

\begin{abstract}
The utility of mixed methods (qualitative and quantitative) is becoming increasingly accepted in health sciences, but substance studies are yet to substantially benefit from such utilities. While there is a growing number of mixed methods alcohol articles concerning developed countries, developing nations are yet to embrace this method. In the Nigerian context, the importance of mixed methods research is yet to be acknowledged. This article therefore, draws on alcohol studies to argue that mixed methods designs will better equip scholars to understand, explore, describe and explain why alcohol consumption and its related problems are increasing in Nigeria. It argues that as motives for consuming alcohol in contemporary Nigeria are multiple, complex and evolving, mixed method approaches that provide multiple pathways for proffering solutions to problems should be embraced.
\end{abstract}

\section{Keywords}

Alcohol problems, Alcohol studies, Mixed methods, Nigerian University students 
A mixed methods way of thinking rests on assumptions that there are multiple legitimate approaches to social inquiry and that any given approach to social inquiry is inevitably partial. Better understanding of the multifaceted and complex character of social phenomena can be obtained from the use of multiple approaches and ways of knowing (Greene 2008, p.20).

\section{Introduction}

In every social inquiry, one of the inquirer's goals is to understand the complex nature of human behaviour and lived experience, but the task of understanding, describing, and explaining "the reality of this complexity is limited by research methods" (Morse 2003, p.189). Following fairly recent developments in the post-industrial societies such as climate change and other social issues arising from consumable goods, many complex problems that hitherto did not exist are springing up. This has heightened the need for nuanced methodologies to unravel these complexities, and for researchers to be better equipped to achieve research objectives of proffering solutions to the problems. Scholars have argued that three main research designs: qualitative, quantitative and mixed methods (Creswell 2009) are available to researchers who are seeking for solutions to social problems, but central to the choice of one or more of these designs is "the nature of research problem, the researcher's personal experiences, and the audiences for the study" (Creswell 2009, p.3).

The aim of this article therefore, is to examine the place of mixed methods research design (qualitative and quantitative) in substance research, especially in light of the Nigerian society. While research in Nigeria has generally been dominated by quantitative scholars, substance (licit and illicit drugs) scholars appear to be increasingly making conclusions pertaining to specific cases from general premises. My purpose is to argue that mixed methods research is a necessity in alcohol research in Nigeria. This is because problematic alcohol consumption cannot be adequately addressed with only quantitative data. It is therefore vital that mixed methods approaches are employed to address the rising alcoholrelated problems in the country because complex problems demand multiple-dimensional pathways to their solutions. The article is divided into four main parts. The ensuing section briefly explores the historical development of mixed methods and offers a concise literature review on the definition and rationales for mixed methods studies. Next, it highlights the findings of mixed methods alcohol studies concerning western countries arguing that their insightful findings could not have been possible with only quantitative methods. Following this, it reviews the methodologies of the identified recent alcohol studies conducted among Nigerian undergraduate students, highlighting their key findings, and against these 
backdrops, discusses why mixed methods designs should be a necessity among Nigerian substance researchers.

\section{A brief Historical Development of Mixed Methods Research}

Research in the behavioural and social sciences was dominated by quantitative, positivist approaches up to the 1950s. The 1950s gave rise to the postpositivists who, despite retaining quantitative approaches, questioned some basic assumptions of the former group (Teddlie and Tashakkori 2003, p.4). Though scholars had sporadically applied qualitative techniques to address research problems in the early 1900s, the rise of qualitative researchers can be traced back to the period between 1970 and 1985 when "researchers such as Eisner, Geertz, Lincoln, Guba, Stake and Wolcott wrote several popular books" that criticised the orientations of the positivists, proposing "a wide variety of qualitative methods" (Teddlie and Tashakkori 2003, p.5).

Suffice to say that scholars have sporadically used mixed methods during the $20^{\text {th }}$ and early $21^{\text {st }}$ centuries to address their different research problems, but "were mostly unaware that they were doing anything out of the ordinary" (Teddlie and Tashakkori 2003, p.5). The birth of mixed methods research can then be placed between 1950 and 1970 during which positivism was debunked and research methodologies called "multimethod or mixed" emerged (Teddlie and Tashakkori 2003, p.6), and the credit for this development can be given to the field of psychology (Creswell 2009). The first study to employ multimethod was conducted by Campbell and Fiske (1959) which combined "more than one quantitative method to measure psychological trait" (Teddlie and Tashakkori 2003, p.6).

The rivalry or "paradigm war" between the positivists and constructivists inbetween this period undeniably helped to develop mixed methods research, and in 1978, Norman Denzin (a sociologist) "introduced the concept- triangulation which involves combining different data sources to study the same social phenomenon" (Teddlie and Tashakkori 2003, p.6-7) while Jick (1979) explicitly explicated its importance in research. It is worthy of note that mixed methods as it is known currently, commenced in the $1980 \mathrm{~s}$ (Creswell and Plano Clark 2011) and credit can be given to scholars who contributed to the growth of this research paradigm. These include: Howe (1988) who introduced the concept of pragmatism to dismiss the notion that quantitative and qualitative paradigms are incompatible (Teddlie and Tashakkori 2003); Greene et al. (1989) who demonstrated the rationales for mixing methods by presenting its typologies, and Morse (1991) who advocated for quantitative and qualitative approaches to be triangulated and introduced the:

use of abbreviations QUAN for quantitative and QUAL for qualitative, the use of plus sign (+) to indicate that data are collected simultaneously (e.g. QUAN + qual), the use 
of the arrow to indicate that data collection occurs sequentially and the use of uppercase to denote more priority given to that orientation [e.g. QUAN] (Teddlie and Tashakkori 2003, p.27).

Other scholars who contributed to the development of mixed methods are Bryman (1988) from the field of management, Creswell (1994) from education, and Morgan (1998) who demonstrated the importance of triangulation in health research and several others too numerous to mention.

\section{Definition of Mixed Methods Research}

From its inception to date, researchers that use mixed methods research design have given it different names such as multitrait-multimethod (Campbell and Fiske 1959), triangulation (Jick 1979), mixed-method (Greene et al. 1989), mixed methods research (Creswell 2009), mixed research (Johnson et al. 2007), etc. While the concepts vary among scholars, none is averse to the fact that, core to mixed methods research is the integration of different methods in a single study (Creswell et al. 2003) which focuses and emphasises on "the same research phenomena and questions" (Moghaddam et al. 2003, p.113). The aforementioned, as well as other scholars have also offered myriad of definitions of what mixed methods research meant to them.

On their part, Freshwater and Cahill (2013, p.4) argue that mixed methods has a double meaning: "it is a set of procedures and a methodological approach" of inquiry. It is "the third research paradigm" (Johnson and Onwuegbuzie 2004, p.15) that provides "multiple paths to meaning" (Wheeldon 2010, p.87) by combining "complementary strengths and non-overlapping weaknesses of quantitative and qualitative research" (Onwuegbuzie and Johnson 2006, p.48). Onwuegbuzie and colleague further explained that "complementary strengths" implies "a putting together of different approaches, methods, and strategies in multiple and creative ways" in a single study (Onwuegbuzie and Johnson 2006, p.52).

To Johnson and Onwuegbuzie (2004, p.17), "mixed methods research is a class of research where the researcher mixes or combines quantitative and qualitative research techniques, methods, approaches, concepts or language in a single study". Because it is a practical, inclusive, creative and expansive method of inquiry, Johnson and colleagues argue that its "primary philosophy is pragmatism" (Johnson et al 2007, p.113); thus, it is "an approach to knowledge (theory and practice) that attempts to consider multiple viewpoints, perspectives, positions, and standpoints" from "qualitative and quantitative research" (Johnson et al. 2007, p.113). Central to the idea of mixed methods research is the fact that the researcher has to consider the kind of data to be elicited, the stage of mixing (e.g. during data collection, analysis or when interpreting the data), type of data to be given weight, 
(e.g. QUAN + qual or QUAL + quan), etc. To address these issues, Creswell and colleagues offered an encompassing definition, arguing that:

mixed methods study involves the collection or analysis of both quantitative and/or qualitative data in a single study in which the data are collected concurrently or sequentially, are given priority and involve the integration of the data at one or more stages in the process of research (Creswell et al. 2003, p.212).

Though many of the researchers that utilize this method of inquiry have defined mixed methods research in different ways, there is not yet a consensus (Creswell et al. 2003), and this may not be unconnected to its relative infancy. In fact, Teddlie and Tashakkori (2003) averred that "mixed methods research is still in its adolescence" (p.3-4), and this arguably is why researchers "do not agree on basic issues related to the field". To address this dialogue, Johnson et al. (2007) sampled the opinion of nineteen leading mixed methods scholars from different backgrounds. Based on the critical analysis of these scholars' opinions, they came up with the ensuing definition:

Mixed methods research is the type of research in which a researcher or team of researchers combines elements of qualitative and quantitative research approaches (e.g. use of qualitative and quantitative viewpoints, data collection, analysis, inference techniques) for the broad purposes of breadth and depth of understanding and corroboration (Johnson et al. 2007, p.123).

It is worthy of note that even though good mixed methods research often integrates and synthesises qualitative and quantitative methods or data, it does not mean that it must be a synthesis of quantitative and qualitative data alone in every inquiry. It can be an integration of two or more different quantitative methods or data such as a combination of survey and experiment; it can also be a combination of multiple qualitative designs such as focus groups and interviews (Yin 2006). Similarly, it can involve a mixing of different types of thematic and numerical data or two sampling methods, for example, probability and nonprobability sampling (Tashakkori and Creswell 2007), and so on. Therefore, mixed methods study is a "research in which the investigator collects and analyses data, integrates the findings, and draws inferences using both qualitative and quantitative approaches or methods in a single study or a program of inquiry" (Tashakkori and Creswell 2007, p.4).

To this end, "its logic of inquiry includes the use of induction [or discovery of patterns), deduction (testing of theories and hypotheses), and abduction (uncovering and relying on the best of a set of explanations for understanding one's results]" (Johnson and Onwuegbuzie 2004, p.17). In the words of Leech and colleague, it largely "represents a research that involves collecting, analysing, and interpreting quantitative data in a single study or a series of studies that investigate the same underlying phenomenon" (Leech and Onwuegbuzie 2009, p.267). Because of these myriad of features inherent in mixed methods 
research designs and the need to delineate mixed methods typologies, Creswell and colleague summed up that in any mixed methods inquiry:

the researcher collects and analyses persuasively and rigorously both qualitative and quantitative data...; mixes (or integrates or links) the two forms of data concurrently by combining them (or merging them), sequentially by having one build on the other, or embedding one within the other; gives priority to one or both forms of data (in terms of what the research emphasizes); uses these procedures in a single study or in multiple of phases of a program of study; frames these procedures within philosophical worldview and theoretical lenses; and combines procedures into specific research designs that direct the plan for conducting the study (Creswell and Plano Clark 2011, p.5).

Though mixed methods is still in its developmental phase as earlier noted (Creswell 2009; Creswell and Plano Clark 2011; Tashakkori and Creswell 2007; Teddlie and Tashakkori 2012), its utilization is gaining currency in social sciences, humanities, health and management sciences. Indeed, scholars from sociology, psychology, economics, health, media, etc., (for example, Woolley 2009; Castro et al. 2010; Bazeley 2012; Plano Clark 2010; Goodwin et al. 2013; Atkinson et al. 2012; Molina-Azorin 2012) have employed it to investigate diverse social issues due to its ability to produce nuanced results in any inquiry if properly selected. Though mixed methods research is becoming popular, it is worthy of note that the aim of mixed methods is not a replacement of qualitative or quantitative methods, but to draw on the strengths of these approaches with cautious minimization of their weaknesses (Creswell and Plano Clark 2011; Onwuegbuzie and Johnson 2006).

\section{Rationales for Mixing Methods in Research}

Over the years, critics of mixed methods inquiry have questioned why researchers should bother with another research paradigm rather than concentrate on the traditional quantitative and qualitative methodologies (Creswell et al. 2003). Advocates of this third research paradigm, however, have produced myriad of evidence and rationales for mixing methods that are clearly difficult to ignore. They often point to the advantages of multiple methods of which neither quantitative nor qualitative method alone can provide (Campbell and Fiske 1959; Johnson and Onwuegbuzie 2004). It is worthy of note that a considerable amount of mixed methods scholars are available, and many of them have explored the benefits of using multimethod over a monolithic method in a single study (e.g. Johnson et al. 2007; Tashakkori and Creswell 2007; Bryman 2007). These and other scholars often claim that every single method has its inherent drawbacks that a combination of methods can easily offset (Creswell et al. 2003). 
In fact, some of the most significant strengths that mixed methods researchers adduce are that mixing methods gives room for several 'better' questions to be asked and answered, diverse perspectives to be explored in a particular study, and if properly documented, can yield useful solutions to local problems (Onwuegbuzie and Johnson 2006). Because of its practical nature, Woolley $(2009$, p.10) noted that it is valuable, especially when eliciting "evidence from young people's perspectives" because the combination of both a qualitative method that "helps in obtaining detailed contextualised information" (Creswell et al. 2003, p.211) and a quantitative method that measures association would paint a "fuller picture" (Woolley. 2009 p.10) of the phenomena being investigated.

Similarly, Creswell and Plano Clark (2011) argue that:

Mixed methods research is practical in the sense that the researcher is free to use all methods possible to address a research problem. It is also practical because individuals tend to solve problems using numbers and words, combine inductive and deductive thinking, and employ skills in observing people as well as recording behaviour (p.13).

To Jick (1979), triangulation of methods enhances the confidence of researchers because the findings are derived from a combination of different sources, methods, approaches or even researchers; thus, it offsets the flaws of both qualitative and quantitative inquiries (Creswell and Plano Clark 2011). Because of this enhancement of credibility, generalizability of findings becomes less problematic. This lends support to Castro et al's (2010, p.345) argument that "under a full integrative perspective, the principal aim is to examine research evidence gathered using both data forms, to generate deep structure conclusions that offer enhanced explanatory power above and beyond the sole use of qualitative or quantitative approach".

Following the development of this third research paradigm and to strengthen the need of employing the design, several attempts have been made by mixed methods scholars to provide a typology of rationales for conducting mixed methods inquiry (Jick 1979; Greene et al. 1989; Collins et al. 2006). Rising from a detailed examination of literature, Bryman (2006) provides a synthesis of the rationales scholars gave for conducting mixed methods research of which some are chronicled as:

1. Triangulation or greater validity: where a researcher or team of researchers combine methods in order to use one finding to corroborate another.

2. Offset- because quantitative or qualitative method has strengths and weaknesses, researchers combine them in a single inquiry so that the combined strengths eliminate their flaws.

3. Completeness: a combination of methods enables an inquiry to have a broad content, unlike those based on a single method. 
4. Different research questions: combination of methods helps researchers to answer diverse qualitative and quantitative questions in a single inquiry.

5. Explanation: a combination of methods avails a researcher an opportunity to utilize findings from one phase to give a thorough explanation of findings from another phase of the inquiry.

6. Unexpected result: mixed researchers often discover that either the qualitative or quantitative phase can yield unexpected findings that are better grasped by using the alternative method.

7. Instrument development: the use of sequential exploratory method can help a researcher to better understand how to word or structure the quantitative instrument.

8. Credibility: when a researcher combines methods, the findings are often more credible.

9. Illustration: data obtained via qualitative instrument can be employed to clarify findings from quantitative phase; this means "putting meat on the bones of dry quantitative findings" (Bryman 2006, p.106).

10. Utility: findings generated by combining methods are more robust in providing solutions to problems.

11. Confirm and discover: when a qualitative phase is implemented first, findings can help to formulate hypotheses that can be tested via quantitative inquiry.

12. Diversity of views: combining methods helps to generate different views that a single method can hardly give.

Further, mixed methods inquiry "allows researchers to combine empirical precision with descriptive precision" (Collins et al. 2006, p.75). Collins and colleagues catalogued four grounds for mixing methods: participant enrichment, instrument fidelity, treatment integrity, and significance enhancement, but this can be subsumed into Greene et al's (1989 p.259) five rationales (triangulation, complementarity, development, initiation and expansion) for mixing methods because this is one of the most valuable syntheses to date of the rationales for combining methods in a single study. Additionally, Teddlie and Tashakkori (2003) outlined three main utilities of mixed methods research stating that "mixed methods research can answer research questions that the other methodologies cannot; provides better (stronger) inferences and provides the opportunity for presenting a greater diversity of divergent views"' (p.14-15).

\section{An Overview of Mixed Methods Alcohol Studies from Western Countries}

Recently, researchers have shown an increased interest in mixed method approaches in substance research. Studies concerning western countries such as the UK, Denmark, Germany, Italy, Norway, USA, Australia, etc., have highlighted its glaring importance. Because of the utilities of mixing methods, a large and growing number of substance 
scholars (e.g. MacNeela and Bredin 2011; Measham and Østergaard 2009; Østergaard 2009; Järvinen and Østergaard 2009; Beccaria and Sande 2003) have drawn on different mixed methods designs to explore and describe alcohol and other drug-related phenomena in these western countries and their findings support the fact that quantitative methods alone is inadequate when studying complex phenomena such as young people and alcohol consumption. For example, by employing questionnaires with female Irish students, MacNeela and Bredin (2011) were able to identify who, among these students, were using alcohol, and to identify the frequency and quantity of alcohol these students consumed. The norms governing how alcohol is drunk, where and when it is consumed, when to stop drinking (due to group limit) and the motives for drinking were revealed by the interviews these scholars conducted. In the interview, participants reported that because they go out in groups and everyone gets drunk, they are always fearless because of the presence of other group members who act as watchdogs. Again, these female students revealed that one of the reasons they drink is because alcohol gives them confidence to approach any boy they love. Understanding this complex social aspect of alcohol consumption is vital in order to find a comprehensive solution to problematic drinking, and this can only be revealed via qualitative approaches.

In the same vein, Østergaard (2009) began by using questionnaire to elicit quantitative data from 2000 young people in Denmark and then conducted follow-up focus group interviews in order to elaborate (Creswell and Plano Clark 2011) on the quantitative data. These approaches yielded divergent results that a single method could not have produced. Some of the insightful findings included the fact that though the participants were aware of the danger of mixing different alcoholic beverages or consuming large quantity of alcohol, party setting and the influence of other party goers inhibited the application of caution (Østergaard 2009). It was also revealed that boys reported that though drinking and losing control is expected of boys, it should not be expected of a girl. On the part of their parents, the qualitative data revealed that many parents believe that their children should drink, make mistakes (get drunk) and learn from their errors in order to know their limit. But, the data also revealed that parents often worried when their children failed to learn from their previous mistakes. Again, these are key social themes on alcohol consumption that may not be adequately addressed with quantitative approaches.

Similarly, Järvinen and Østergaard's (2009) study that combined quantitative and qualitative approaches captured the social theme concerning adolescents' alcohol consumption in Denmark. For example, there was a "collective truth" among participants "that parental rules are useless because adolescent self-government is the only way to control drinking"' (Järvinen and Østergaard 2009, p. 382-383). Additionally, it was revealed that some female participants believed that when parents set rules on how and what their children should drink, it means they do not trust their children and that this hinders the children from growing to maturity. Similarly, it was reported that some boys whose parents 
disallow them to drink consider themselves as losers. These insightful findings are complex and only qualitative methods can capture them.

Though Guise and Gill (2007) and Coleman and Cater's (2005a) studies reported only qualitative data, they started by using short questionnaire to select those who use alcohol. Having elicited alcohol users, they applied diverse qualitative methods and this produced insightful findings such as drinking and having sexual intercourse with a stranger because of intoxication, intentionally getting drunk to behave anti-socially so as to blame alcohol (Coleman and Cater 2005a), drinking to have confidence and getting drunk because it is a "harmless fun" (Guise and Gill 2007, p.900). Other scholars such as Brener et al. (2010) also applied quantitative and qualitative methods to study how clients are treated in drug rehabilitation homes in Australia. Additionally, Atkinson et al. (2012) combined survey and content analysis to explore how alcohol is gendered in female and male magazine in UK while Stoller et al. (2009) drew on exploratory sequential design to examine decision making among non-abusing alcohol drinkers in the USA, and the list is unending.

\section{Exploring the Methods of Alcohol Research in Nigeria}

\section{Inclusion Criteria}

In this section, I will review studies that examined scholarly articles conducted recently in Nigeria. Studies that examined alcohol-related issues such as alcohol abuse, misuse, motives for consuming alcohol and alcohol-related problems among Nigerian university students between 2000 and 2013 were considered. Studies included are those that were conducted among the student population, while studies that combined student and nonstudent population were excluded. The rationales for restricting the scope to Nigerian university students are of three fold. Firstly, alcohol research is undeniably at infant stage in Nigeria (Dimah and Gire 2004), but a considerable number of studies have been conducted among the student population.

Additionally, it has been reported that alcohol use, misuse and alcohol-related problems are often higher among students than non-student population in many countries (Wemm et al. 2013; Wechsler et al. 2002; Dawson et al. 2004; Vicary and Karshin 2002), and this arguably, is one of the reasons for concentrating on student population by Nigerian researchers. Lastly, substance research in Nigeria is dominated by academics, and with the growing alcohol-related problems in Nigeria, they are more likely to use the best method known to them as well as easily accessible participants, which for them is university population. Thus, the level and quality of alcohol research in Nigeria can arguably be measured based on the studies conducted by these academics. 


\section{Search Method}

A Thorough search of Cochrane Library, MEDLINE, PsycLIT, PubMed and Sociological Abstracts was undertaken in order to identify studies conducted between January 2000 and July 2013. Additionally, I searched through Google Scholar and the African Journal of Drug and Alcohol Studies which is the main substance peer review journal in Nigeria, with the aim of identifying recent literature. The keyword combination for the search includes: "alcohol abuse in Nigerian universities/tertiary institution", "alcohol misuse among Nigerian students", "patterns of alcohol use in the Nigerian universities", "perceived benefits of alcohol among Nigerian students', "alcohol adverts, marketing and promotion in the Nigerian universities" and "alcohol use disorders among Nigerian university undergraduates". Following this, the articles identified were screened to determine their relevance by examining their titles and abstracts. Those that met the criteria were further screened by exploring their methods sections. In all, ten studies were included. It is worth noting that this period (2000-2013) was chosen because since Nigeria returned to democratic governance in 1999, many socio-political constraints that were extant during the military rule have been lifted, and this arguably has facilitated the increasing alcohol marketing, availability and consumption on various Nigerian university campuses.

\section{Results}

Though the search method yielded over 25 titles (published in peer review and non-peer review journals), only 13 studies were published in peer review journals between 2000 and 2013. After further screening, three studies were eliminated. Two studies (Makanjuola et al. 2007; Abikoye and Adekoya 2010) did not examine only alcohol while Odenigbo et al. (2013) combined student and nonstudent populations. Among the ten studies included, eight were conducted in western Nigeria; one was conducted in the eastern Nigeria while one was conducted in southern Nigeria. No study from northern Nigeria was identified for inclusion. The result shows that all the ten studies had quantitative designs.

Olley and Ajiteru (2001) employed a 76-item questionnaire to examine the determinants of alcohol use among 525 female students of the University of Ibadan while Adewuya (2005) validated the World Health Organization's (WHO) Alcohol Use Disorders Identification Test (AUDIT) questionnaire among 810 students of Obafemi Awolowo University. Similarly, Adewuya et al. (2006) employed the WHO's Composite International Diagnostic Interview to measure alcohol use and anxiety differentials among male and female students of Obafemi Awolowo University, and Adewuya (2006) conducted a crosssectional survey employing questionnaire and Mini International Neuropsychiatric Interview among 2658 students of six tertiary institutions in the western Nigeria. On their part, Adewuya et al. (2007) conducted a cross-sectional survey among 2658 undergraduate students in Osun State to determine the prevalence and correlates of alcohol use disorders while Olley's (2008) study was a cross-sectional survey of 841 freshmen in University of 
Ibadan. He adopted a 93-item questionnaire that combined "six mutually exclusive scales" to measure risky behaviours due to harmful alcohol use.

Abikoye and Osinowo (2011) in another survey of 1705, purposively selected students of three universities in western Nigeria; they adopted the AUDIT questionnaire to measure the perception of students who patronize drinking joints. Chikere and Mayowa (2011) also employed self-administered structured questionnaire to describe the prevalence and perceived health effect of alcohol use among 482 male undergraduate students in Owerri, eastern Nigeria. Additionally, Abayomi et al. (2013) employed three different sets of questionnaires to describe the psychosocial correlates of undergraduates' hazardous alcohol use in western Nigeria and Umoh et al. (2012) adopted an item from AUDIT to build a 16-item structured questionnaire which they administered to a convenient sample of 492 students of southern Nigerian university on perception of alcohol promotion, availability and policy.

\section{Discussion and Conclusion}

\section{The Necessities of Mixed Methods designs in Alcohol Research in Nigeria}

As earlier stated, social inquiries often address complex phenomena that often cannot be adequately addressed by qualitative or quantitative methods alone (Creswell 2009). Thus, scholars argue that mixed methods research has become a necessity, especially for studies that aimed at addressing complex and sensitive issues that a single method may inadequately capture. This is because any study that properly combines multiple methods in inquiries that require multiple approaches will produce nuanced results that cannot be rivalled by a mono-method study. Scholars such as Newman et al. (2003) posited that "quantitative research paradigm is designed to address questions that hypothesize relationships among variables that are measured frequently in numerical and objective ways" while qualitative research is designed to address questions of meaning, interpretation, and socially constructed realities" (p.170). Because each has weaknesses, combining them will increase validity, reliability and inferences due to the fact that researchers can draw on their strengths which will produce "convergent and divergent evidence about the phenomenon being studied" (Johnson and Turner 2003, p.299).

Undeniably, not every social inquiry demands mixed methods design (Greene 2008) because the appropriateness of a method depends on the goals of a project, in that "methods themselves have no intrinsic value" (Silverman, 2011, p.166), but some studies will require a combination of words and figures to paint a fuller picture and yield richer results. Though the focus of this paper is on the ten studies, it is worth noting that all the identified studies had quantitative designs. None among the ten studies under consideration combined quantitative and qualitative (QUAN and QUAL) designs, none was 
qualitative, and despite the fact that they were all quantitative studies, none even adopted a longitudinal method. This has serious implication on generalizability of their findings which is the main reason quantitative scholars often adduce.

That all the studies were conducted with quantitative design, is unsurprising. This in part, is because substance research globally is dominated by positivists. In the Nigerian context, medical doctors, epidemiologists, pharmacists, public health experts, etc., known for quantitative research dominate substance studies, and this arguably is why mixed methods or qualitative methods have been underutilized. My aim is not to belittle quantitative design or to reify the importance of qualitative research because "the nature of the research problem" is part of what determines the choice of design (Creswell 2009, p.3) and mixed methods research is not aimed at discarding the former group (see Creswell and Plano Clark 2011; Onwuegbuzie and Johnson 2006). The emphasis of the article is on the fact that there are some important aspects of alcohol usage that can only be investigated using qualitative or mixed methods approaches. Therefore, continued neglect of mixed methods research, especially a combination of qualitative and quantitative design in a single study in Nigeria will perpetuate the growing alcohol-related problems because combining methods, data, approaches, etc. in a study is sine qua non to understanding complex problems due to the potentials of producing divergent views or findings from such a combination.

That no study among these students in Nigeria combined QUAN and QUAL or adopted QUAL has serious implications. Understanding why young Nigerians use and misuse alcohol requires a research method that will allow the researcher to capture the daily lived experience of these young people due to several reasons. Firstly, alcohol is a sensitive and complex issue in Nigeria. Because mixed methods research helps to investigate sensitive topics better than any other methods (Creswell et al. 2003), employing it can help unravel the inherent sensitivities in Nigeria. Why alcohol is a sensitive issue in Nigeria, is because young people and women are culturally restrained from alcohol consumption in many communities. For example, they were excluded from alcohol consumption in the traditional epoch due to sociocultural or religious constraints (Odejide et al. 1987), but in contemporary Nigeria, this group is drinking hazardously with diverse frightening motives (Abikoye and Adekoya 2010; Chikere and Mayowa 2011; Abayomi et al. 2013). Because of this paradigm shift in alcohol consumption among young people and women in Nigeria, many alcohol-related problems that hitherto did not exist between 1960 and 1990s are extant in contemporary Nigeria, and many of these phenomena may not be properly addressed with a single method, especially "quantitative fixed-choice" design that often fails to capture the social theme of any inquiry (Silverman 2011, p.166).

For example, two studies (Abikoye and Osinowo 2011; Chikere and Mayowa 2011) reported that students use alcohol to enhance sexual performance. This finding is a sensitive one attributable to myriad of reasons, one such is how some alcoholic beverages 
are advertised in Nigeria (Obot and Ibanga 2002). If these scholars applied qualitative approach as Guise and Gill (2007) and Coleman and Cater (2005a) did in their studies in Europe, they would have produced more insightful findings that will help in proffering solutions to this sensitive result. This is because these students would have narrated why and how they use alcohol for sexual pleasure and possibly where such was learnt. Additionally, Chikere and colleague's findings revealed that some of the students drink because they want to be identified among the group of happening guys on campus. The rationale behind these sensitive and complex findings would have been properly addressed if qualitative follow-up studies were conducted for several reasons because studies conducted before 2000 did not report such findings in Nigeria.

That alcohol is used for the construction of social identity (being among the group of happening guys) is also novel in Nigeria because intoxication among adult males (who were culturally permitted to drink) in the traditional Nigerian society attracted punishment (Oshodin 1995). Had Chikere and his colleague conducted interviews or focus groups, may be they would have uncovered reason(s) for this social change which arguably is due to the influence of globalization because studies conducted in Denmark reported that young people used drunkenness as a resource for constructing social identity, but this finding was only possible due to the application of qualitative methods (Demant and Järvinen 2006). Because qualitative methods such as interviews help to capture how people "actively construct their social world", Chikere and colleague would have been better positioned to elicit richer and insightful data on the participants' experiences with alcohol by asking questions on why and how these students use alcohol consumption as a password to the world of fame on campus (Silverman 2011, p.169) despite the fact that young people are culturally supposed to be teetotallers in the part of Nigeria they studied. Arguably, further probing would have revealed if these youths are drinking out of rebellion against the status quo or that it is because of the effect of globalization that is spreading across all facets of contemporary Nigeria. Again, a well-structured "why-question" may have revealed if it is engendered by the Nigerian media via aggressive adverts that often portray drinking and bonding among youths, associating alcohol with famousness and success (Dumbili 2013b) or something else.

Again, while Abikoye and colleague's study sampled male and female students, Chikere and colleague elicited their data from only males. No reason was given for excluding females, but this arguably is because of the difficulties of convincing Nigerian females to participate in such sensitive surveys. In a male-dominated society like Nigeria, drunkenness by males may be pardoned in most communities (Ikuesan 1994). This may not be the case with females because a known female alcoholic may not just be seen as feckless and a social misfit, her family honour would have been dragged to the mud, to the extent of preventing other females from her family from being married (Ikuesan 1994). Therefore, females are always reluctant in participating in such studies. Mixed methods provide us with "diversity in service of both better understanding and greater equity voice" (Greene 2008, p.20), and 
also have potentials of understanding and "addressing social inequalities" (Mertens 2013, p.217). Thus, female participants would have been recruited by employing "participantselection variant" of sequential explanatory mixed method (Creswell and Plano Clark 2011, p.86) or what Morgan (1998) calls the "preliminary quantitative methods" (p.369).

This method involves using the questionnaire to elicit samples for the second phase of the qualitative study. Because confidentiality can be guaranteed through this method, this would have equipped Chikere and colleague to identify females that drink and follow them up with interviews (telephone interview if need be) to hear their views. Similarly, Nigerian females arguably are marginalised from alcohol consumption due to sociocultural issues, and because mixed methods research often yield rich results that can be used to "create better living conditions for marginalized members of society" (Mertens 2013 p.251), sequential transformative design would have been employed. This is because it "creates sensitivity to collecting data from marginalized or underrepresented groups, and ends with a call to action" to better the fortune of the marginalized group (Creswell 2009, p.212). If these scholars had adopted mixed methods, they arguably may have been able to elicit data from females that can further help in proffering solutions to rising alcohol-related problem in Nigeria.

Studies conducted earlier in Nigeria (Olley and Ajiteru 2001; Room and Selin 2005) argued that Nigerian females drink hazardously and suffer serious alcohol-related problems. In the same vein, scholars from Europe and America have argued that one of the reasons young females drink is to be bold to approach boys they like (Coleman and Cater 2005b). Because over $50 \%$ of the males that Chikere and colleague sampled reported that they use alcohol to enhance sexual performance, females may be drinking for such reasons as Klein (2001) reported among nonstudent population in Nigeria. Thus, excluding females have not painted the fuller picture, and this invariably has serious implications on the findings because even though they came from a quantitative study, they cannot be transferred or generalized in "other desired Nigerian settings or populations" (Kemper et al. 2003, p.275).

Johnson and Onwuegbuzie (2004) have argued that researchers armed with the "fundamental principle of mixed research should collect multiple data using different strategies, approaches, and methods in such a way that the resulting mixture or combination is likely to result in complementary strengths and non-overlapping weaknesses" (p.18). Creswell (2009) also posited that the qualitative data are usually used for the interpretation of the quantitative data as well as for examining and explaining any "unexpected findings" (Morse 2003, p.192) from the first stage, while Greene (2008) argued that "a mixed methods way of thinking also generates questions, alongside possible answers; it generates results that are both smooth and jagged, full of relative certainties alongside possibilities and even surprises, offering some stories not yet told" (p.20). Because of the mutual interdependence of the datasets (Morse 2003), adopting mixed methods research would have aided Olley (2008) to unravel the surprising reasons $7.2 \%$ of 
his participants exchange sex for alcohol because it has never been reported in Nigeria before 2008 and would have also equipped Umoh et al. (2012) to discover why alcohol users do not want alcohol availability to be regulated despite the rising alcohol-related problems easy availability (Dumbili 2013a) is causing in Nigeria. Again, it would have aided Chikere and colleague to discover why $52.1 \%$ of those sampled declared that they will not quit episodic drinking despite being aware of the consequences of harmful consumption. This is because MacNeela and Bredin's (2011) study in Ireland, Beccaria \& Sande's (2003) study of Norway and Italy and others from Denmark that utilised qualitative methods reported similar findings, and this has been attributed to many factors, one such being the growing culture of intoxication among young people (Piacentini and Banister 2009) who see drunkenness as a resource as well as social capital (Demant and Järvinen 2010).

Denscombe (2008) argued that "researchers use mixed methods to improve the accuracy of their data, whereas others use it to produce a more complete picture by combining information from complementary kinds of data sources" (p.272). This scholar added that mixed methods is used to eliminate biases inherent in a particular method as well as "used as a way of developing the analysis and building on initial findings using contrasting kinds of data and methods" (p.272). That none of these quantitative studies under review adopted longitudinal methods, and that seven (Olley and Ajiteru 2001; Adewuya 2005; Adewuya et al. 2006; Olley 2008; Chikere and Mayowa 2011; Abayomi et al. 2013; Umoh et al. 2012) out of the ten studies did not elicit representative samples, further questions the trustworthiness of their findings (Kemper et al. 2003). Despite the fact that mixed methods research has its cost in terms of time, money and skills, the benefits must be the driving force for its utilization in Nigeria. The biases inherent in these studies would have been avoided if "participant-selection variant" of sequential explanatory mixed method (Creswell and Plano Clark 2011, p.86) was adopted because the emphasis is often placed on qualitative (quan + QUAL) results and not on generalization of results when this method is used. Thus, few participants can be elicited in a study, yet with trustworthy results.

Undeniably, conducting a research in Nigeria poses different problems due to the complexity of diverse cultures and religions. In the northern Muslim-dominated part of the country for instance, socio-religious constraints often hinder researchers (especially males) from accessing female participants. This arguably is why no study was identified from that region. Thus, this set of people from the north can be reached by triangulating researchers (females and males) and via telephone interviews while males can be included in quantitative studies because alcohol and other psychoactive substances are used in the north even though they are under-reported (Abdulmalik et al. 2009). The result of such studies can be reported in phases before proper integration. This is because Creswell et al. (2003) have argued that "when two phases of data collection exist, the researcher typically reports the data collection process in two phases. The report may also include an analysis of each phase of data separately and the integration of information in the discussion or conclusion section of a study" (p.218). 
It is also argued that mixed methods research is the best strategy for "explaining and interpreting relationships" (Creswell 2009, p.211). Two of the studies (Adewuya et al. 2006; Abayomi et al. 2013) examined the relationships between alcohol, psychological wellbeing and anxiety. These relationships would have been better captured by follow-up explanations variant of sequential explanatory mixed methods (Creswell and Plano Clark 2011) where emphasis is placed on the quantitative phase (i.e. QUAN + qual) but using the qualitative to explain the quantitative findings. The benefit is because sequential explanatory method is easy to implement due to the distinct nature of the phases, and it is also straightforward (Creswell and Plano Clark 2011), having the ability to provide explicit ways of describing and reporting findings (Creswell 2009). It equally avails the researcher the chance of testing and validating results of the quantitative findings in the qualitative phase (Wheeldon 2010). As these Nigerian researchers are positivists, this method would have been much easier for them to utilise while their findings remain reliable.

Additionally, mixed methods research gives researchers leeway to use multiple pathways to address research problems. It is practical as earlier stated, and because of its practicality, Woolley (2009) argues that it is valuable, especially when eliciting "evidence from young people's perspectives" (p.10). This is because both a combination of qualitative method that does not just "helps in obtaining detailed contextualised information" (Creswell et al. 2003, p.211), but provides "in-depth understanding of phenomenon" that is being studied without necessarily looking for validation (Denzin 2012, p.82) and quantitative methods that often describe statistical relationships can yield nuanced results. The ten studies were conducted among young people, yet, none captured their lived experiences qualitatively. Employing mixed methods design (QUAN + qual or QUAL + quan) would have allowed these young people to reveal in detail the role of alcohol in their daily lives that quantitative study alone cannot cover. Asking why and how questions would have captured the social theme that no other method can as well as yielding findings that can help to reduce alcohol-related problems in the country.

In sum, the paper has given an account for the rationale for using mixed methods in substance studies. Because of the increasing alcohol-related problems that the dominance of quantitative research in Nigeria has not been able to address, it is important that qualitative or mixed methods studies are now conducted. Despite the challenges of conducting mixed methods research as pointed out earlier, it should not be jettisoned by alcohol researchers in Nigeria and other developing countries because there are many unique aspect of alcohol consumption (such as drinking to enhance sexual performance or alcohol and social identity) that can only be identified via qualitative or mixed methods approaches. It is necessary to understand these and other key social themes in order to devise comprehensive solutions to problematic alcohol consumption in Nigeria. Therefore, Nigeria alcohol researchers should embrace the fact that mixed methods or wholly qualitative research has become a necessity because as the motives for alcohol consumption are becoming increasingly socio-culturally (de)constructed among young 
Nigerians and alcohol-related problems are multiplying and evolving in contemporary Nigeria, proffering solutions to them should also follow multiple pathways that will capture the underpinning complex social variables instead of just looking for statistical significance. It is believed that these social variables can only be unravelled via studies that combined qualitative and quantitative methods or simply qualitative methods that often capture people's lived-experience.

\section{References}

Abayomi O., Onifade P.O., Adelufosi A.O., Akinhanmi A.O.: Psychosocial correlates of hazardous alcohol use among undergraduates in south-western Nigeria. Gen. Hosp. Psychiatry. 35, 320-324 (2013)

Abdulmalik J., Omigbodun O., Beida O., Adedokun B.: Psychoactive substance use among children in informal religious schools (Almajiris) in northern Nigeria. Mental Health, Religion and Culture 12, 527-542 (2009)

Abikoye G. E., Osinowo H.O.: In the eye of the beholder: Alcohol use and perceptions among student-patrons of 'Joints' in three Nigerian university communities. Psychological Studies 56, 258-265 (2011)

Abikoye G. E., Adekoya J.A.: Predicting substance abuse in a sample of Nigerian undergraduate students: The role of core self-evaluations and delay of gratification. Psychological Studies 55, 299-307 (2010)

Adewuya A. O., Ola B.A., Aloba O.O.: Gender differences in the relationship between alcohol use and anxiety symptoms among Nigerian college students. Drug Alcohol Depend. 85, $255-257$ (2006)

Adewuya A. O.: Validation of the alcohol use disorders identification test (audit) as a screening tool for alcohol-related problems among Nigerian university students. Alcohol and Alcoholism 40, 575-577 (2005)

Adewuya A. O.: Prevalence of major depressive disorder in Nigerian college students with alcohol-related problems. Gen. Hosp. Psychiatry. 28, 169-173 (2006) 
Adewuya A., Ola B., Aloba O., Mapayi B., Ibigbami O., Adewumi T.: Alcohol use disorders among Nigerian university students: Prevalence and sociodemographic correlates. Nigerian Journal of Psychiatry 5, 5-9 (2007)

Atkinson A., Kirton A., Sumnall H.: The gendering of alcohol in consumer magazines: An analysis of male and female targeted publications. Journal of Gender Studies 21, 365386 (2012)

Bazeley P.: Integrative analysis strategies for mixed data sources. Am. Behav. Sci. 56, 814$828(2012)$

Beccaria F., Sande A.: Drinking games and rite of life projects: A social comparison of the meaning and functions of young people's use of alcohol during the rite of passage to adulthood in Italy and Norway. Young 11, 99-119 (2003)

Brener L., von Hippel W., von Hippel C., Resnick I., Treloar C.: Perceptions of discriminatory treatment by staff as predictors of drug treatment completion: Utility of a mixed methods approach. Drug Alcohol Rev. 29, 491-497 (2010)

Bryman A.: Barriers to integrating quantitative and qualitative research. Journal of Mixed Methods Research 1, 8-22 (2007)

Bryman A.: Integrating quantitative and qualitative research: How is it done? Qualitative Research 6, 97-113 (2006)

Bryman A.: Quantity and quality in social research. Rutledge, London (1988).

Campbell D. T., Fiske D.W.: Convergent and discriminant validation by the multitraitmultimethod matrix. Psychol. Bull. 56, 81-105 (1959)

Castro F. G., Kellison J.G., Boyd S.J., Kopak A.: A methodology for conducting integrative mixed methods research and data analyses. Journal of Mixed Methods Research 4, $342-360(2010)$

Chikere E. I. C., Mayowa M.O.: Prevalence and perceived health effect of alcohol use among male undergraduate students in owerri, south-east Nigeria: A descriptive crosssectional study. BMC Public Health 11, 118 (2011)

Coleman L., Cater S.: Underage 'binge' drinking: A qualitative study into motivations and outcomes. Drugs: Educ. Prev. Policy 12, 125-136 (2005a)

Coleman L. M., Cater S.M.: A qualitative study of the relationship between alcohol consumption and risky sex in adolescents. Arch. Sex. Behav. 34, 649-661 (2005b) 
Collins K. M., Onwuegbuzie A.J., Sutton I.L.: A model incorporating the rationale and purpose for conducting mixed methods research in special education and beyond. Learning Disabilities: A Contemporary Journal 4, 67-100 (2006)

Creswell J.W., Plano Clark V.L.: Designing and conducting mixed methods research. SAGE Publication Inc., Thousand Oaks (2011)

Creswell J.W., Plano Clark V.L., Gutmann M.L., Hanson W.E.: Advanced mixed methods research designs. In: A. Tashakkori and C. Teddlie (ed.) Handbook of mixed methods in social and behavioural research, pp. 209-240. Sage Pub, Thousand Oaks (2003)

Creswell J.W.: Research Design-Qualitative \& Quantitative Approaches. SAGE Publications, Thousand Oaks (1994)

Creswell J.W.: Research design: qualitative, quantitative, and mixed method approaches. Sage, London (2009)

Dawson D. A., Grant B.F., Stinson F.S., Chou P.S.: Another look at heavy episodic drinking and alcohol use disorders among college and non-college youth. Journal of Studies on Alcohol and Drugs 65, 477 (2004)

Demant J., Järvinen M.: Social capital as norms and resources: Focus groups discussing alcohol. Addiction Research and Theory 19, 91-101 (2010)

Demant J., Järvinen M.: Constructing maturity through alcohol experience-focus group interviews with teenagers. Addiction Research \& Theory 14, 589-602 (2006)

Denscombe M.: Communities of practice a research paradigm for the mixed methods approach. Journal of Mixed Methods Research 2, 270-283 (2008)

Denzin N. K.: Triangulation 2.0. Journal of Mixed Methods Research 6, 80-88 (2012)

Dimah A., Gire J.T.: The health and economic consequences of alcohol use in central Nigeria. African Journal of Drug and Alcohol Studies 3, 44-53 (2004)

Dumbili E.: Changing Patterns of Alcohol Consumption in Nigeria: An Exploration of Responsible factors and Consequences. Medical Sociology Online, 7, 20-33 (2013a)

Dumbili E.W.: The politics of alcohol policy in Nigeria: A critical analysis of how and why brewers use strategic ambiguity to supplant policy initiatives. Journal of Asian and African Studies 1-15. Doi: 10.1177/0021909613490137. (2013b)

Freshwater D., Cahill J.: Paradigms lost and paradigms regained. Journal of Mixed Methods Research 7, 3-5 (2013) 
Goodwin R., Polek E., Goodwin K.: Perceived changes in health and interactions with "the paracetamol force": A multimethod study. Journal of Mixed Methods Research 7, 152$172(2013)$

Greene J. C.: Is mixed methods social inquiry a distinctive methodology? Journal of Mixed Methods Research 2, 7-22 (2008)

Greene J. C., Caracelli V.J., Graham W.F.: Toward a conceptual framework for mixed-method evaluation designs. Educational Evaluation and Policy Analysis 11, 255-274 (1989)

Guise J. M. F., Gill J.S.: 'Binge drinking? it's good, it's harmless fun': A discourse analysis of accounts of female undergraduate drinking in Scotland. Health Educ. Res. 22, 895-906 (2007)

Howe K. R.: Against the quantitative-qualitative incompatibility thesis or dogmas die hard. Educational Researcher 17, 10-16 (1988).

Ikuesan B. A.: Drinking problems and the position of women in Nigeria. Addiction 89, 941944 (1994)

Järvinen M., Østergaard J.: Governing adolescent drinking. Youth and Society 40, 377-402 (2009)

Jick T. D.: Mixing qualitative and quantitative methods: Triangulation in action. Adm. Sci. Q. 24, 602-611 (1979)

Johnson R.B., Turner L.A.: Data collection strategies in mixed methods research. In: A. Tashakkori and C. Teddlie (ed.) Handbook of mixed methods in social and behavioural research, pp. 273-296. SAGE Publ., Thousand Oaks (2003)

Johnson R. B., Onwuegbuzie A.J., Turner L.A.: Toward a definition of mixed methods research. Journal of Mixed Methods Research 1, 112-133 (2007)

Johnson R. B., Onwuegbuzie A.J.: Mixed methods research: A research paradigm whose time has come. Educational Researcher 33, 14-26 (2004)

Kemper E.A., Stringfield S., Teddlie C.: Mixed methods sampling strategies in social science research. In: A. Tashakkori and C. Teddlie (ed.) Handbook of mixed methods in social and behavioural research, pp. 273-296. Sage Publ, Thousand Oaks (2003)

Klein A.: "Have a piss, drink ogogoro, smoke Igbo, but don't take gbana"-hard and soft drugs in Nigeria: A critical comparison of official policies and the view on the street. J. Psychoactive Drugs 33, 111-119 (2001) 
Leech N. L., Onwuegbuzie A.J.: A typology of mixed methods research designs. Quality and Quantity 43, 265-275 (2009)

MacNeela P., Bredin O.: Keeping your balance freedom and regulation in female university students' drinking practices. Journal of Health Psychology 16, 284-293 (2011)

Makanjuola A. B., Daramola T.O., Obembe A.O.: Psychoactive substance use among medical students in a Nigerian university. World Psychiatry 6, 112-114 (2007)

Measham F., Østergaard J.: The public face of binge drinking: British and Danish young women, recent trends in alcohol consumption and the European binge drinking debate. Probation Journal 56, 415-434 (2009)

Mertens D. M.: Emerging advances in mixed methods addressing social justice. Journal of Mixed Methods Research 7, 215-218 (2013)

Moghaddam F.M., Walker B.R., Harre R.: Cultural distance, levels of abstraction, and the advantages of mixed methods. In: A. Tashakkori and C. Teddlie (ed.) Handbook of mixed methods in social and behavioural research, pp. 111-134. SAGE, Thousand Oaks (2003).

Molina-Azorin J. F.: Mixed methods research in strategic management impact and applications. Organ. Res. Methods 15, 33-56 (2012)

Morgan D. L.: Practical strategies for combining qualitative and quantitative methods: Applications to health research. Qual. Health Res. 8, 362-376 (1998)

Morse J.M.: Principles of mixed methods and multimethod research design. In: A. Tashakkori and C. Teddlie (ed.) Handbook of mixed methods in social and behavioural research, pp. 189-208. SAGE Publ, Thousand Oaks (2003).

Morse J. M.: Approaches to qualitative-quantitative methodological triangulation. Nurs. Res. 40, 120-123 (1991)

Newman I., Ridenour C.S., Newman C., DeMarco Jr, George Mario Paul: A Typology of Research Purposes and its Relationship to Mixed Methods. In: A. Tashakkori and C. Teddlie (ed.) Handbook of mixed methods in social and behavioural research, pp. 167188. Sage Publications, Incorporated, Thousand Oaks (2003)

Obot I., Ibanga A.: Selling booze: Alcohol marketing in Nigeria. The Globe 2, 6-10 (2002)

Odejide O. A., Ohaeri J., Adelekan M.L., Ikuesan B.: Drinking behaviour and social change among youths in Nigeria--A study of two cities. Drug Alcohol Depend. 20, 227-233 (1987) 
Odenigbo A., Agbo S., Atinmo T.: Alcohol consumption pattern of habitual drinkers in Nigeria. Alcoholism Treatment Quarterly 31, 141-149 (2013)

Olley B. O., Ajiteru A.: Determinants of alcohol use among female University students in Nigeria. Journal of Social Sciences 5, 161-167 (2001)

Olley B.: Child sexual abuse, harmful alcohol use and age as determinants of sexual risk behaviours among freshmen in a Nigerian university. Afr. J. Reprod. Health $12,75-88$ (2008).

Onwuegbuzie A. J., Johnson R.B.: The validity issue in mixed research. Research in the Schools 13, 48-63 (2006)

Oshodin O.G.: Nigeria. In: Heath B.D. (ed.) International handbook on alcohol and culture, pp. 213-223. Greenwood Press, Westport (1995)

Østergaard J.: Learning to become an alcohol user: Adolescents taking risks and parents living with uncertainty. Addiction Research \& Theory 17, 30-53 (2009)

Piacentini M. G., Banister E.N.: Managing anti-consumption in an excessive drinking culture. Journal of Business Research 62, 279-288 (2009).

Plano Clark V. L.: The adoption and practice of mixed methods: US trends in federally funded health-related research. Qualitative Inquiry 16, 428-440 (2010).

Room R., Selin K.H.: Problems from women's and men's drinking in eight developing countries. In: IS Obot and R. Room (ed.) Alcohol, gender and drinking problems: Perspectives from low and middle income countries, pp. 209-210. World Health Organization, Geneva (2005)

Silverman D.: Interpreting qualitative data. Sage Publications Limited, London (2011).

Stoller E. P., Webster N.J., Blixen C.E., McCormick R.A., Hund A.J., Perzynski A.T., Kanuch S.W., Thomas C.L., Kercher K., Dawson N.V.: Alcohol consumption decisions among non-abusing drinkers diagnosed with hepatitis C: an exploratory sequential mixed methods study. Journal of Mixed Methods Research 3, 65-86 (2009)

Tashakkori A., Creswell J.W.: Editorial: The new era of mixed methods. Journal of Mixed Methods Research 1, 3-7 (2007)

Teddlie C., Tashakkori A.: Common "Core" characteristics of mixed methods research: A review of critical issues and call for greater convergence. Am. Behav. Sci. 56, 774-788 (2012) 
Teddlie C., Tashakkori A.: Major issues and controversies in the use of mixed methods in the social and behavioural sciences. In: A. Tashakkori and C. Teddlie (ed.) Handbook of mixed methods in social and Behavioral research, pp. 3-50. SAGE Pub., Thousand Oaks, California (2003)

Umoh O. O., Obot P.P., Obot I.: Perception of alcohol availability, promotion and policy by Nigerian university students. African Journal of Drug and Alcohol Studies 11, 107-116 (2012)

Vicary J. R., Karshin C.M.: College alcohol abuse: A review of the problems, issues, and prevention approaches. Journal of Primary Prevention 22, 299-331 (2002)

Wechsler H., Lee J.E., Hall J., Wagenaar A.C., Lee H.: Secondhand effects of student alcohol use reported by neighbours of colleges: The role of alcohol outlets. Soc. Sci. Med. 55, 425-435 (2002)

Wemm S., Fanean A., Baker A., Blough E.R., Mewaldt S., Bardi M.: Problematic drinking and physiological responses among female college students. Alcohol 47, 149-157 (2013)

Wheeldon J.: Mapping mixed methods research: Methods, measures, and meaning. Journal of Mixed Methods Research 4, 87-102 (2010)

Woolley C. M.: Meeting the mixed methods challenge of integration in a sociological study of structure and agency. Journal of Mixed Methods Research 3, 7-25 (2009)

Yin R. K.: Mixed methods research: Are the methods genuinely integrated or merely parallel. Research in the Schools 13, 41-47 (2006) 